\title{
PRÁTICAS DA MATEMÁTICA MODERNA NO CURSO DE LICENCIATURA: uma perspectiva histórico-cultural
}

\author{
Pratice of modern matematics in the teaching degree \\ course: a historical-cultural perspective
}

\author{
Neuza Bertoni Pinto ${ }^{a}$, Elenir Terezinha Paluch Soares ${ }^{b}$ \\ a Professora do Programa de Pós-Graduação em Educação da PUCPR, \\ Curitiba, Paraná - Brasil, e-mail: neuzard@uol.com.br \\ b Mestranda do Programa de Pós-Graduação em Educação da PUCPR, \\ Curitiba, Paraná - Brasil, e-mail: epaluch5@hotmail.com
}

\begin{abstract}
Resumo
O presente estudo, parte da pesquisa em andamento no Programa de Pós-Graduação -Mestrado em Educação - da Pontifícia Universidade Católica do Paraná, tem como objetivo compreender as finalidades das práticas de Matemática Moderna efetivadas no curso de Licenciatura em Matemática em uma instituição de ensino superior no interior paranaense, turma-1970-1973, período em que o Movimento da Matemática Moderna encontrava-se em plena expansão nos cursos de Licenciatura em Matemática no Brasil. O estudo, de abordagem histórica, utiliza conceitos da história cultural, referenciados em Chervel (1990), Certeau (1989) e Julia (2001). As práticas pedagógicas de Matemática Moderna, vivenciadas no curso investigado, foram caracterizadas a partir dos dados obtidos nos arquivos da instituição, em documento escolar fornecido por
\end{abstract}

Rev. Diálogo Educ., Curitiba, v. 8, n. 23, p. 91-104, jan./abr. 2008 
licenciando, ex-aluno do curso investigado, contendo anotações de aulas, conteúdos e exercícios desenvolvidos em sala de aula na disciplina Fundamentos da Matemática Elementar, além de depoimentos de ex-alunos da referida turma. Nas análises são contemplados os conteúdos de Matemática Moderna priorizados pelo professor formador, a bibliográfica recomendada aos licenciandos, o material didático utilizado nas aulas e os procedimentos didático-metodológicos. As análises preliminares apontam que a Matemática Moderna foi introduzida no curso de Licenciatura pela disciplina Fundamentos da Matemática Elementar, orientada por uma concepção formalista de ensino de Matemática, com a finalidade de repassar e ampliar a compreensão dos modernos conteúdos matemáticos trazidos pelo movimento, contribuindo para o melhor desempenho docente dos formandos, professores que na época já se encontravam em exercício nas escolas de primeiro e segundo graus do estado do Paraná.

Palavras-chave: Licenciaturas; Práticas pedagógicas; Matemática moderna.

\begin{abstract}
The present paper, which starts from the research that has been developed in the Pos Graduation course - Master in Education Pontifícia Católica do Paraná, aims at understanding the objectives of modern mathematics practice in the mathematics teaching degree course, which is developed in a public institution of higher education, in Parana state, class 1970-1973, period in which the movement of modern mathematics was in its plenitude and expansion in the teaching degree courses, in Brazil. The study, with an historical approach, makes use of concepts from cultural history, the ones that are referred in Chervel (1990), Certeau (1989) and Julia (2001). The pedagogical practices of modern mathematics, faced in the mentioned course, were characterized by the data obtained in the files of the institution, in curricular documents, which were provided by graduating students, ex students, containing notes from classes, contents and exercises developed during the class of Fundamental Elementary Mathematics, besides ex students testimonies. In the analysis, the focus is on the contents of modern mathematics chosen by the professor, the bibliography
\end{abstract}


recommended to the graduating students, the didactic material used in the classes and the methodological-didactic procedures. The previous analyses show that the modern mathematics was introduced in the teaching degree course through the discipline named Fundamental Elementary Mathematics, guided by an instructional conception of mathematics learning, and searching for passing on and enlarging the understanding of modern mathematics contents which were brought by the movement, contributing to a better teaching performance of the graduating students, professors who were already working in the elementary and high schools, in Paraná state.

Keywords: Teaching degree course; Pedagogical practices; Modern mathematics.

Considerado um marco na história da Educação Matemática, o Movimento da Matemática Moderna (MMM) imprimiu mudanças significativas na matemática escolar dos diferentes níveis da educação brasileira. Na década de 1970, momento de grande expansão dos cursos de licenciaturas no Brasil, essas mudanças ganham intensidade nos cursos de formação de professores de Matemática, introduzindo novos desafios à formação dos licenciandos.

Com o objetivo de conhecer e compreender como as idéias do movimento foram apropriadas nos referidos cursos, o presente estudo tem por objetivo analisar as práticas pedagógicas efetivadas no curso de Licenciatura em Matemática de uma instituição de ensino superior do interior paranaense, turma1970-1973, época em que o MMM encontrava-se em plena expansão nas escolas brasileiras. Valendo-se de procedimentos da história cultural, o estudo considera a relevância dessa vertente interpretativa para a escrita da História da Educação Matemática, em especial para a historiografia do Movimento da Matemática Moderna. De acordo com João Bosco Pitombeira de Carvalho:

O Movimento da Matemática Moderna foi o maior experimento já feito em educação matemática. Assim, qualquer pessoa que se interesse pelo ensino da matemática, quer do ponto de vista acadêmico, de pesquisa, quer do ponto de vista histórico, quer como professor de matemática engajado pessoalmente no ensino, deveria tomar conhecimento desse assunto. Sua compreensão é essencial para entender por que se ensina matemática como hoje em dia. (CARVALHO, 1988, p. 15).

Rev. Diálogo Educ., Curitiba, v. 8, n. 23, p. 91-104, jan./abr. 2008 
Reconstituir a história dessas práticas implica na busca de compreensão como foram apropriadas as idéias do movimento pelos futuros professores da educação básica, uma busca das heranças de um passado ainda recente que deixou marcas no presente. Ao analisar as características dessas práticas, é possível detectar traços da apropriação do MMM, pelo professor formador, no sentido dado por Chartier (1990), ${ }^{1}$ ou seja, do uso que fez em sua ação pedagógica das idéias modernizadoras, seja reforçando ou modificando aspectos da cultura escolar já existentes. Ao desvelar a ação criativa de professores e alunos, o estudo das práticas de apropriação contribui, sobremaneira, para a compreensão das finalidades que orientaram a formação dos professores para o ensino da Matemática Moderna. Consideramos a cultura escolar como a definiu Julia (2001, p. 10): "um conjunto de normas que definem os conhecimentos a ensinar e condutas a inculcar, e um conjunto de práticas que permitem a transmissão desses conhecimentos e a incorporação desses comportamentos; normas e práticas coordenadas a finalidades que podem variar segundo as épocas (finalidades religiosas, sociopolíticas ou simplesmente de socialização)".

As fontes utilizadas para o presente estudo correspondem a um conjunto de registros realizados por licenciando dessa turma, referentes à apresentação dos conteúdos e exercícios desenvolvidos em sala de aula na disciplina Fundamentos da Matemática Elementar, além de depoimentos de ex-alunos dessa turma acerca das práticas pedagógicas que orientavam a aprendizagem dos alunos.

\section{As práticas pedagógicas na perspectiva histórico-cultural}

Segundo Chervel (1990), o termo "disciplina" e a expressão "disciplina escolar", até o final do século XIX, eram utilizados no sentido de vigilância atitudinal, ou seja, repressão de condutas prejudiciais à boa ordem da escola; hoje, disciplina escolar é entendida como aquilo que se ensina, a instrução que o aluno recebe, o conteúdo ou matéria de ensino. Para esse historiador, a história dos conteúdos constitui o componente central, o "pivô" que possibilita a compreensão da verdadeira finalidade da disciplina escolar. As grandes finalidades ou objetivos educacionais que variam segundo as épocas e emergem conforme as demandas emanadas da sociedade global em contínua evolução acabam determinando os conteúdos de ensino. Sob essa perspectiva, a função das disciplinas escolares consiste em "colocar os conteúdos de instrução a serviço de uma finalidade educativa" (CHERVEL, 1990, p. 191).

CHARTIER (1990, p. 136-137), Considera que o uso que as pessoas fazem dos objetos que lhes são distribuídos ou dos modelos que lhes são impostos é uma questão desafiadora para a história cultural, pois há sempre uma prática diferenciada na apropriação dos objetos colocados em circulação, a aceitação das novas mensagens opera-se segundo ele, "através de ordenamentos, de desvios, de reempregos singulares que são o objecto fundamental da história cultural".

Rev. Diálogo Educ., Curitiba, v. 8, n. 23, p. 91-104, jan./abr. 2008 
Compreendendo-se disciplina escolar não apenas como práticas docentes em sala de aula, mas também como expressão das grandes finalidades que a constituem e que podem exercer um significativo papel na sociedade global, procuramos, nesse estudo, indagar como foram inseridos os conteúdos de Matemática Moderna nos cursos de Licenciaturas, na década de 1970.

Na perspectiva histórico-cultural, o estudo considera o que afirmou Chervel (1990, p. 191), "no coração do processo que transforma as finalidades em ensino, há a pessoa do docente" que tem diante de si apenas um verdadeiro limite para sua liberdade pedagógica: o grupo de alunos que encontra à sua frente.

Visto desse modo, pesquisar as práticas pedagógicas efetivadas em determinado período pode contribuir para o desvelamento das reais finalidades educacionais daquela época. E, particularmente, se o foco da pesquisa são práticas desenvolvidas em uma determinada disciplina em um curso de licenciatura, é possível encontrar vestígios de como este curso cumpria seu objetivo maior e explícito de formação docente.

Chervel alega que os períodos de renovação do sistema educacional são momentos privilegiados para o historiador, por entendê-los como portadores de objetivos declarados circunstancialmente e por forçarem o docente a se lançar por sua própria conta em caminhos ainda não trilhados. As mudanças propostas pelo Movimento da Matemática Moderna, acontecimento de abrangência internacional, também foram introduzidas no currículo de formação de professores de Matemática, modificando substancialmente os programas das disciplinas e os manuais didáticos. No Brasil, esse fato ocorre a partir da segunda metade da década de 60.

Segundo o pesquisador e historiador francês Dominique Julia (2001, p. 19), "mais que nos tempos de calmaria, é nos tempos de crise e de conflitos que podemos captar o melhor funcionamento real das finalidades atribuídas à escola". Os historiadores citados defendem a importância de um exame atento das transformações das disciplinas escolares, dos materiais escolares produzidos por professores e alunos, enquanto vestígios materiais das reais finalidades de uma disciplina escolar. Interessar-se pela análise dessa materialidade escolar é, segundo Julia (1990), uma forma de compreender como foram ensinados os conteúdos de um componente curricular e de conhecer traços da cultura escolar de um determinado momento histórico. Os exercícios escolares são, assim, considerados pelos dois autores como o coração da disciplina, a "caixa preta" da escola, quando utiliza uma metáfora aeronáutica, para explicar seu entendimento de que a história de uma disciplina escolar revela suas reais finalidades.

Rev. Diálogo Educ., Curitiba, v. 8, n. 23, p. 91-104, jan./abr. 2008 


\section{A constituição das fontes de pesquisa}

Segundo Certeau (1982), o historiador necessita ser cuidadoso tanto na constituição como na interpretação de documentos, lembrando que a história não é uma crítica epistemológica e que aquilo que parece ser um fato é ainda apenas um indício; que as práticas mudam seus significados e sentidos no curso de diferentes períodos históricos, de modo que toda interpretação histórica depende de um sistema de referência.

A instituição investigada configura-se como um dos raros estabelecimentos paranaenses de ensino superior que ofereciam Licenciatura em Matemática no interior do estado, ao tempo do Movimento da Matemática Moderna.

Segundo dados obtidos no Órgão de Apoio Acadêmico, na Secretaria Geral da Instituição e nos depoimentos de ex-alunos, a turma de 1970-1973 foi a pioneira do referido curso, com 43 alunos matriculados no $1^{\circ}$ ano, dentre os quais, 36 concluíram o curso no tempo mínimo de 4 anos. Um terço do total de alunos matriculados eram residentes em outros 13 municípios, totalizando assim, com os alunos do município-sede, 14 municípios paranaenses, beneficiando-se da formação docente fornecida pela instituição, sendo que $90 \%$ dos licenciandos já eram professores de Matemática atuantes na rede pública estadual de educação paranaense e/ou na rede particular de ensino. O curso, dividido em quatro períodos letivos anuais, possuía uma carga horária de 2640 horas. A disciplina Fundamentos de Matemática Elementar correspondia a 150 horas no $1^{\circ}$ ano e 120 horas no $2^{\circ}$ ano. Para o presente estudo, foram também coletados depoimentos de dois exalunos da primeira turma do Curso de Licenciatura em Matemática, professores ainda em exercício no magistério superior. Ao inventariar fontes históricas para a pesquisa que nos propusemos realizar, tomamos conhecimento do material produzido por um aluno da primeira turma de licenciados em Matemática dessa Instituição de Ensino Superior, período 1970-1973, época em que a Matemática Moderna estava em pleno vigor nos currículos das escolas paranaenses. ${ }^{2}$

O referido material constitui-se de duas encadernações, contendo as anotações feitas no quadro-de-giz pelos professores formadores das aulas ministradas nas diversas disciplinas do curso Licenciatura em Matemática da referida instituição e que foram cuidadosamente registradas, na época, por um

\footnotetext{
2 No Paraná o grupo NEDEM, coordenado pelo professor e então diretor do Colégio Estadual do Paraná, destacou-se como principal disseminador das idéias do MMM, com a realização de cursos de formação continuada, publicação de coleção de livros didáticos para o ensino do primeiro grau e participação nas diretrizes curriculares de Matemática propostas pela Secretaria Estadual de Educação do Paraná.
}

Rev. Diálogo Educ., Curitiba, v. 8, n. 23, p. 91-104, jan./abr. 2008 
ex-aluno do curso. Essa produção visava repassar conteúdos das aulas dadas para aqueles alunos que às vezes deixavam de presenciá-las pelo difícil deslocamento de seus municípios de origem até o município sede da Instituição, sendo um deles distante aproximadamente $400 \mathrm{~km}$.

O autor desse material, após assistir as aulas, repassava as anotações registradas pelos professores formadores no quadro-de-giz, para um estêncil, reproduzindo os textos em mimeógrafo a álcool, um tipo de reprodução muito utilizado na época, visto que ainda não eram disponíveis os recursos tecnológicos atuais. Vendia-os aos colegas, obtendo recursos para cobrir os custos com o próprio curso que, embora público, inicialmente era pago pelo acadêmico. $\mathrm{O}$ primeiro volume encadernado é referente ao ano 1970, correspondente ao primeiro ano letivo do curso de Licenciatura em Matemática e, contém, dentre outros, registros das aulas de Fundamentos de Matemática Elementar, disciplina que apresentou aos licenciandos a Teoria dos Conjuntos, Relações e Funções, citados por Fiorentini (1995) como elementos unificadores dos três campos fundamentais da Matemática, ao se referir aos propósitos do Movimento da Matemática Moderna. No segundo volume, referente ao ano 1971, encontramse registrados os conteúdos de Lógica da Matemática, outra grande bandeira defendida pelo Movimento da Matemática Moderna.

Nesse estudo, centraremos nossa análise nos depoimentos coletados e nos registros que constam no primeiro volume do material selecionado, em especial no capítulo referente à Teoria dos Conjuntos, por ter sido esta tratada mais intensamente nos demais níveis de escolaridade, especialmente nos livros didáticos de Matemática em circulação na década de 1970. A essa fonte levantaremos os seguintes questionamentos: Como era trabalhada a disciplina Fundamentos de Matemática Elementar, no Curso de Licenciatura em Matemática? Quais conteúdos da Matemática Moderna foram apresentados pelo professor de Fundamentos de Matemática Elementar? Qual concepção pedagógica que orientava o trabalho do professor formador nessa disciplina? Que finalidades educativas estavam implícitas na disciplina responsável pela introdução da Matemática Moderna aos licenciandos?

\section{Características das práticas pedagógicas: análises preliminares}

Depoimentos fornecidos por dois ex-alunos dessa turma indicam que a disciplina Fundamentos de Matemática Elementar contemplava, prioritariamente, conteúdos e práticas da Matemática Moderna, especialmente no $1^{\circ}$ ano do curso. As aulas da referida disciplina eram preferencialmente expositivas e acompanhadas de anotações no quadro-de-giz dos títulos e subtítulos das unidades de conteúdos, definições, propriedades, exercícios e

Rev. Diálogo Educ., Curitiba, v. 8, n. 23, p. 91-104, jan./abr. 2008 
demonstrações. Segundo os ex-alunos, a habilidade do professor formador para ministrar a disciplina superava o normal, sendo considerado como um exemplo didático a ser seguido. O livro didático, recomendado aos licenciandos e utilizado pelo professor, era Teoria dos Conjuntos, de Seymour Lipschutz. Sua edição original havia sido publicada nos Estados Unidos, em 1964, por Schaum Publishing Co. com o título Set Theory and Related Topics. As referências ao seu autor apresentam-no como Ph.D. do Departamento de Matemática do Polytechnic Institute of Brooklyn. O prefácio escrito pelo autor traz, entre outras, indicações de que esse livro-texto trata da Teoria dos Conjuntos de uma maneira informal e não axiomática, apontando-o como referência para qualquer nível; informa também que a apresentação de certos tópicos estão influenciados pelas preferências do autor, citando, como exemplo, que as funções são apresentadas antes das relações e não são definidas inicialmente como conjuntos de pares ordenados. Consta também que cada capítulo principia com proposições claras de definições pertinentes, princípios e teoremas, com material ilustrativo e descritivo, seguindo-se de problemas graduados, resolvidos e suplementares, os quais servem para ilustrar e ampliar a teoria, focalizando os pontos nos quais o estudante se sentia inseguro e "provendo a repetição de princípios básicos", que na concepção do autor, "são tão vitais ao aprendizado eficiente" (LIPSCHUTZ, 1968, Prefácio). Comenta ainda o autor, no prefácio do livro, que entre os problemas, incluíam-se demonstrações de teoremas e derivações dos resultados básicos, além de sugestões bibliográficas. ${ }^{3}$

Os conteúdos contemplados em sala de aula, no $1^{\circ}$ ano da disciplina Fundamentos de Matemática Elementar, foram: Teoria Elementar dos Conjuntos, Funções e Relações. Porém, limitaremos nossas análises em torno da Teoria dos Conjuntos, em função da inviabilidade de contemplar todos os tópicos nesse trabalho. Nesse item do programa, foram abordados os seguintes tópicos: conceitos intuitivos de conjunto elemento e relação de pertinência; definições de conjuntos finitos e infinitos; definição de conjuntos iguais, utilizando frases bicondicionais do tipo "se e somente se" e as propriedades reflexiva, simétrica e transitiva da igualdade; definições de conjuntos desiguais, conjunto vazio, subconjunto, subconjunto próprio, também utilizando frases bicondicionais do tipo "se e somente se"; apresentação do conjunto de potência, conjuntos comparáveis e não comparáveis, conjuntos disjuntos, conjunto universal ou conjunto universo; diagramas de Venn-Euler; diagramas em Linhas; definições das operações de conjuntos: intersecção e união, suas propriedades idempotentes, comutativas, associativas e distributivas; definições de diferença entre dois conjuntos e de complementar ou complemento de um

BOURBAKI, Nicolas. Theorie des Ensembles. Paris: Hermann, 1958; HALMOS, P. R. Naive Set Theory. Van Nostrand, 1960.

Rev. Diálogo Educ., Curitiba, v. 8, n. 23, p. 91-104, jan./abr. 2008 
conjunto; demonstrações (do tipo provar que...) das propriedades apresentadas, utilizando os conceitos primitivos, as definições e a simbologia dos conjuntos (símbolo de pertence, não pertence, está contido, não está contido, união, intersecção, diferença, complementar e quantificador universal).

Os registros informam que a maioria das definições era acompanhada de exemplos numéricos ou literais e algumas demonstrações seguidas de comprovações numéricas, insinuando uma intenção de clarificá-las.

Pelos depoimentos do ex-alunos, na metodologia de aulas expositivas, prioritariamente utilizada na apresentação dos conteúdos, eram freqüentes a repetitividade de modelos preestabelecidos nos exercícios e demonstrações. As aulas partiam da apresentação de conceitos primitivos (termos e relações não definidas) e, apesar da não utilização explícita das palavras axioma e teorema, o professor privilegiava as definições e demonstrações, marcas do pensamento axiomático que permeava a Matemática Moderna. No material fornecido pelo ex-aluno, observamos nas definições uma forte presença do uso de frases bicondicionais do tipo "se e somente se", muito utilizadas nas proposições lógicas, o que denota a estreita relação entre as proposições lógicas e as operações com conjuntos.

Os exercícios propostos pelo professor formador, segundo os registros analisados, sugerem um docente comprometido com a contextualização da Teoria dos Conjuntos, na medida em que potencializava na aplicação dessa Teoria, no que se refere a representação tabular de conjuntos, a utilização de importantes ferramentas matemáticas, como operações com números reais e complexos, a resolução de equações do $2^{\circ}$ grau, biquadradas, exponenciais e trigonométricas. Tais registros sugerem o comprometimento do professor em assegurar aos seus discípulos, o conhecimento da Teoria dos Conjuntos na visão do matemático, aquele que vê sentido no ensino da matemática por ela mesma, ou seja, numa concepção formalista do ensino dessa ciência.

Como indicam os exercícios contidos no documento analisado, o ensino da disciplina pautava-se pela transmissão do conhecimento do professor para os alunos. Os recursos audiovisuais existentes na época e disponíveis naquela instituição, segundo os ex-alunos, eram o quadro-de-giz e o giz colorido. No entanto, a postura do professor, e sua habilidade na utilização de tais recursos, é apontada por um dos entrevistados como suficientes para envolver os licenciandos em situações de aprendizagem, afirmando sua satisfação em tê-lo como professor e beneficiar-se de suas aulas, como indica o seguinte depoimento:

[...] O modo simpático e claro com que o professor dessa matéria a transmitia, despertava na gente mais gosto pela matéria e até um querer imitá-lo na sua didática, pois gostava muito de suas aulas e a gente aprendia. (Entrevistado A, 2006 ).

Rev. Diálogo Educ., Curitiba, v. 8, n. 23, p. 91-104, jan./abr. 2008 
No material analisado, observamos também a marcante utilização de ilustrações em diagramas antecedendo e acompanhando as definições. No entanto, isso não se apresenta suficiente para caracterizar o uso do método indutivo. Há uma ausência significativa do uso do método heurístico, muito difundido ao tempo do MMM, um procedimento voltado para o aluno descobrir, por si mesmo, a verdade anunciada na definição. A maioria das definições, seguidas de demonstrações, são acompanhadas de comprovações numéricas, sugerindo uma intenção de clarificar a idéia apresentada e atribuir-lhe credibilidade.

\section{As finalidades da disciplina fundamentos da matemática elementar}

Apesar de o livro adotado apresentar, além da Teoria Elementar dos Conjuntos, a teoria dos números cardinais e ordinais à maneira clássica de Cantor, conjuntos parcialmente ordenados e Bem-Ordenados, Indução Transfinita, o Axioma de Escolha e seus equivalentes, incluindo o lema de Zorn, paradoxos da Teoria dos Conjuntos e outros tópicos, observamos, nas anotações do ex-aluno, a prioridade dada pelo professor aos tópicos da Matemática Moderna, ou sejam: Teoria dos Conjuntos, Relações e Funções, conteúdos que eram também abordados nos livros didáticos dos níveis mais elementares de escolaridade. Nas anotações das aulas, é visível a preocupação do professor em utilizar a simbologia matemática atualizada, por exemplo, quando a mesma definição é apresentada por ele em duas formas: utilizando palavras e na seqüência, usando a simbologia dos conjuntos.

Quais motivos teriam levado o professor formador a fazer essa seleção de conteúdos? De acordo com a Lei 5540/684 (CARVALHO, 1975, p. 83-99), uma das finalidades das Licenciaturas era a formação técnica de profissionais para suprir a defasagem quantitativa de mão-de-obra especializada que correspondesse às exigências do mercado de trabalho, cuja política educacional em vigor estava voltada para o desenvolvimento e modernização do capital.

O exposto nos remete as idéias defendidas por Chervel, ao se referir a uma via de mão dupla: a sociedade determinando as finalidades das disciplinas e as finalidades das disciplinas por meio dos conteúdos e das práticas pedagógicas, atuando sobre a sociedade, "formando uma cultura que vem por sua vez penetrar moldar, modificar a cultura da sociedade global" (CHERVEL, 1990). Ao tratar das finalidades do ensino escolar, esse autor adverte:

4 A Lei 5.540/68, estabelecida durante o regime militar de governo iniciado em 1964, e alinhada com os acordos MEC-USAID, fixou normas de organização e funcionamento do ensino superior e sua articulação com a escola média.

Rev. Diálogo Educ., Curitiba, v. 8, n. 23, p. 91-104, jan./abr. 2008 
Estima-se ordinariamente, de fato, que os conteúdos de ensino são impostos como tais à escola pela sociedade que a rodeia e pela cultura na qual se banha. Na opinião comum, a escola ensina as ciências, as quais fizeram suas comprovações em outro local. Ela ensina a gramática, porque a gramática, criação secular dos lingüistas, expressa a verdade da língua; ela ensina as ciências exatas, como a matemática, e, quando ela se envolve com a matemática moderna é, pensa-se, porque acaba de ocorrer uma revolução na ciência matemática [...] (CHERVEL, 1990, p. 180).

No Parecer no 292/62 (BRASIL, 1974, p. 213-216) do Conselho Federal de Educação, os currículos mínimos das Licenciaturas compreendiam as matérias fixadas para o bacharelado, "convenientemente ajustadas em sua amplitude e os estudos profissionais que habilitem ao exercício do magistério nos estabelecimentos de Ensino Médio" (CANDAU, 1987, p. 19). Isso sugere que a prioridade dada pelo professor da referida disciplina, ao realizar um trabalho mais demorado com a Teoria Elementar dos Conjuntos, agiu em função das necessidades dos licenciandos, a maioria já professores em exercício no ensino de primeiro e segundo graus (hoje ensino fundamental e médio), em dominar melhor um conhecimento novo, tendo em vista que a Matemática Moderna chegou para eles via livro didático.

$\mathrm{Na}$ percepção de um dos ex-alunos do curso investigado, a Matemática Moderna valorizava a apreensão, pelo aluno, das estruturas matemáticas:

A Matemática Moderna estava voltada às estruturas da Matemática, com a Matemática em si, numa visão mais internalista [...] Uma coisa é você ensinar Matemática e outra coisa é você fazer a ciência matemática [...] Como professor de Licenciatura, a minha grande preocupação sempre foi trabalhar com o ensino da Matemática; não sou matemático, sou professor de Matemática. (Entrevistado B, 2006).

A par do ensino formalístico, mencionado no depoimento do exaluno B, fica evidente a preocupação do professor formador em instrumentalizar tecnicamente os licenciandos, já professores no desempenho de suas funções docentes no ensino de $1^{\circ}$ e $2^{\circ}$ graus, como é apontado no depoimento de outro ex-aluno, ao falar das aulas de Matemática Moderna:

Rev. Diálogo Educ., Curitiba, v. 8, n. 23, p. 91-104, jan./abr. 2008 
A coisa parecia inicialmente meio estranha [...] A gente pensava o que aquilo tinha a ver com a realidade do aluno e com o dia a dia do estudante. E realmente a gente não via muita ligação entre a Teoria dos Conjuntos e os problemas cotidianos [...] A minha preocupação maior era corresponder ao desempenho do professor. O professor estava expondo, fazendo o seu trabalho e ele iria me cobrar o trabalho dele. Então, eu teria que nas provas pagar o que o professor havia dado. Era importante o desempenho do professor ali, eu creio, em desenvolver o gosto pela matéria, e, também, no incentivo para a transmissão daquela matéria em nossa prática na sala de aula (Entrevistado A, 2006).

Para os estudos históricos que estamos desenvolvendo, essa constatação é muito significativa, ao apontar para uma relação apreciável entre os estudos feitos pelos licenciandos de Matemática, na época, e suas necessidades técnico-profissionais, tendo em vista que os conteúdos listados eram os preferencialmente recomendados pelos programas do ensino de primeiro e segundo graus da época.

\section{CONSIDERAÇÕES FINAIS}

Os cursos de Licenciatura da década de 1970, no Brasil, contribuíram para a disseminação das principais mudanças propostas pelo Movimento da Matemática Moderna. O presente estudo focalizou como a disciplina Fundamentos da Matemática Elementar, componente do currículo do Curso de Licenciatura em Matemática de uma instituição paranaense, abordava os conceitos modernos, em especial, a Teoria de Conjuntos, principal eixo temático do movimento.

As análises, ora apresentadas, constituem apenas uma pequena amostra das práticas pedagógicas da Matemática Moderna, concretizadas em 1970, num Curso de Licenciatura em Matemática do estado do Paraná, entretanto, fornecem indícios de como as idéias modernizadoras da Matemática foram acolhidas pela instituição formadora e apropriadas pelos alunos, em sua formação acadêmica.

Tais análises nos levam a supor, também, que na seleção de conteúdos, o professor da referida disciplina considerou o momento ímpar que os educadores matemáticos viviam, envoltos em inúmeras interrogações trazidas pelo movimento. Os materiais produzidos pela disciplina Fundamentos de

Rev. Diálogo Educ., Curitiba, v. 8, n. 23, p. 91-104, jan./abr. 2008 
Matemática Elementar revelam que o professor, ao adequar seus conteúdos curriculares às necessidades imediatas do seu público, parece ter procurado atender às finalidades maiores de um curso de licenciatura emergente, ou seja, preparar os licenciandos para ministrar aulas de Matemática Moderna. Visto desse modo, esse movimento de cunho internacional, gerado em parte pela insatisfação de uma sociedade ávida por desenvolvimento científico-tecnológico, em relação à instrução matemática institucionalizada, propiciou mudanças na matemática escolar, na medida em que reorganizou não apenas os conteúdos programáticos da disciplina Matemática, mas também se preocupou com a atualização dos professores que já atuavam no ensino de primeiro e segundo graus. $\mathrm{O}$ tratamento pedagógico dado à Teoria dos Conjuntos na disciplina analisada tinha por finalidade não apenas vulgarizar o conhecimento sobre essa teoria, mas assessorar os professores licenciandos que precisavam desse conhecimento para o melhor desempenho de suas funções docentes em níveis de escolaridade anteriores ao superior. A escola, como campo de forças contraditórias, ao mesmo tempo em que reproduz, gera transformações na sociedade. Nesse sentido, a apropriação do MMM pelos cursos de Licenciaturas, mesmo mantendo a tradição formalista da cultura acadêmica, centrada na construção do edifício matemático, cumpriu uma finalidade histórica, ao disseminar, na formação dos licenciandos, a proposta programática trazida pelo movimento, introduzindo conceitos fundamentais da nova linguagem indispensável à educação científica suscitada pela nova sociedade tecnológica que despontava no cenário mundial.

\section{REFERÊNCIAS}

BRASIL. CFE. Parecer 292/62. Currículos mínimos dos cursos de nível superior. Brasília, 1974. p. 213-216.

CANDAU, V. M. F. (Coord.). Novos rumos da licenciatura. Brasília: INEP; Rio de Janeiro: PUCRJ, 1987. (Série estudos e pesquisas).

CARVALHO, Guido I. Ensino Superior: legislação e jurisprudência. São Paulo: Revista dos Tribunais, São Paulo, v. 1, p. 83-99. 1975.

CARVALHO, J. B. Pitombeira de. As idéias fundamentais da matemática moderna. Boletim Gepem, Rio de Janeiro, ano 13, n. 23, p. 7-24, 1988.

CHARTIER, R. A história cultural: entre práticas e representações. Lisboa: Difel, 1990.

CERTEAU, M. de. A escrita da história. Rio de Janeiro: Forense, 1982.

Rev. Diálogo Educ., Curitiba, v. 8, n. 23, p. 91-104, jan./abr. 2008 
CHERVEL, A. História das disciplinas escolares: reflexões sobre um campo de pesquisa. Revista Teoria \&Educação, Porto Alegre, n. 2, p. 177-229, 1990.

FIORENTINI, D. Alguns modos de ver e conceber o ensino da Matemática no Brasil. Revista Zetetiké, São Paulo, UNICAMP, ano 3, n. 4, p.1-37, 1995.

JULIA, D. A cultura escolar como objeto histórico. Tradução de Gizele de Souza. Revista Brasileira de História da Educação, Campinas, n. 1, 09 44, jan./jun. 2001.

LIPSCHUTZ, S. Teoria dos conjuntos. Tradução do Engenheiro Fernando Vilain Heuri da Silva. Rio de Janeiro: Ao Livro Técnico S.A., 1968. (Coleção SCHAUM).

Recebido: 30/10/2007

Received: 10/30/2007

Aprovado: 05/11/2007

Approved: 11/05/2007

Rev. Diálogo Educ., Curitiba, v. 8, n. 23, p. 91-104, jan./abr. 2008 